\title{
Forecasting Transportation Infrastructure Needs Using System Dynamics in Tanjung Perak Port
}

\author{
Kevin Arga ${ }^{\# 1}$, Budi Susetyo ${ }^{* 2}$, Syafwandi ${ }^{\# 3}$ \\ \# Department of Civil Engineering, Mercu Buana University, Jakarta, Indonesia \\ ${ }^{1}$ kevinarga08@gmail.com \\ ${ }^{2}$ budi.susetyo@mercubuana.ac.id \\ ${ }^{3}$ syafwandi@menarasiswa.ac.id
}

\begin{abstract}
This research implement system dynamics method to forecasting transportation Infrastructure needs in Tanjung Perak Port. Container activities in this port have not been maximized due to infrastructure needs that are still not optimal where the growth of container flows in this port reaching $\mathbf{7 . 4 3 \%}$. By using the system dynamic approach, an analysis of interrelated parameters is carried out to see the cause and effect relationship of these parameters in determining infrastructure needs by adding port capacity or by developing alternative transportation infrastructure. Simulations are carried out to see the conditions for the next 20 years using two scenarios. In scenario 1, it will be obtained in 2026 that conditions will occur where the installed capacity of the port will have problems serving the flow of containers to the maximum or an average of around $11.11 \%$ of containers will not be optimally absorbed until 2034 . Results from scenario 2 are obtained, in In 2025 there will be conditions where the installed capacity of the port will experience problems in serving container flow to the maximum or an average of around $10 \%$ of containers will not be absorbed to the maximum until 2034. From the results of the simulation of both scenarios, the construction of alternative transportation infrastructure is needed to serve containers that are not absorbed optimally.
\end{abstract}

Keyword - System Dynamics, Forecasting, Modelling, Infrastructure Transportation.

\section{INTRODUCTION}

Transportation infrastructure is a key factor for the economic growth and competitiveness of a country, as well as the economic and social development of a region [1]. Increased energy supply and transportation infrastructure are the foundation for regional economic development and increased accessibility[2]. Transportation infrastructure projects are projects that require a high investment to be realize. Therefore in planning a transportation infrastructure project there needs to be planning and feasibility studies in advance. Investment in transportation infrastructure has a generative and distribution effect on economic value and activities between regions. The impacts of transportation infrastructure development can be classified into construction (temporary or short-term) and operational and maintenance (structural or long-term) impacts [3]. The impact of construction refers to the investment costs to the output and demand prices of market commodities and services during the construction phase. The impact of operation and maintenance includes the cost of capital accumulation as a result of increased accessibility during the operation and maintenance phase

This means that transportation infrastructure development must be on target and on time following the needs of the region. Right on target means according to the region's demands and needs, while on time means that transportation infrastructure development is not too late in overcoming problems that occur in the region. An analysis is needed to see the relationship between the parameters that influence the demand for transportation infrastructure. Scenarios for the analysis are also needed to see the sensitivity of the analysis of the relationship of these parameters.

Transportation infrastructure is very complicated and often involves several stakeholders that produce feedback with different time lags between responses [4]. The approach with the system dynamics method can be used as a way of analyzing the needs of transportation infrastructure. By using the system dynamics method we can see the relationship between interrelated parameters that result in market demand for infrastructure transportation system dynamics are depictions of system behavior that have interdependent relationships and change with time.

System dynamics have the advantage of connecting and modeling from various parameters analyzed so that all parameters have a causal relationship. Besides, the system dynamics approach can also describe the dynamics of the behavior of time to know the past, present, and future conditions. Several studies using the system dynamics method in transportation infrastructure projects such as using system dynamics to make demand forecasting modeling to increase the feasibility value bridge construction [5]. Using system dynamics to make a model of the impact of the feasibility study on the success of the project at the construction stage [6]. Using system dynamics method to make model of the container requirements and the policy for transportation plans at the port [7]. 
The purpose of this study is to conduct an analysis and modeling of transportation infrastructure needs measured from several interrelated parameters. Several scenarios are also carried out to see the sensitivity of the analysis so that the transportation infrastructure can be right on target according to the needs and timely in anticipating problems that occur due to the system dynamics absence of the transportation infrastructure. By knowing the time of transport infrastructure demand, good and maximum planning can be done on several aspects such as finance, resources, target/market, and government policies during the construction, operation, and maintenance. Thus the high investment costs in transportation infrastructure projects will be following the benefits generated.

\section{METHODOLOGY}

System Dynamics method is used as an approach in this study to help see the cause and effect of various variables and predict future conditions. System Dynamics is used in this study to see the cause and effect of various conditions, situations, or various variables that arise in this study based on the activities that occur. The models and simulations developed in this study were created using specialist software for system dynamics and decision making, namely Powersim Studio 10. Data collection using surveys and time-series data related to the parameters to be analysed.

System Dynamics is a method that provides a deeper understanding of problems and their variants in the form of formal mathematical modeling and computer simulations of complex, nonlinear, and dynamic systems where feedback loops are needed to capture relationships between various variables [8]. System Dynamics developed in the 1950s by Forrester has a philosophy of systems thinking where everything is connected in a dynamic and complex system [9]. Forrester uses computer simulations to see the impact of time on the problem. System Dynamics shows how most decision-making policies are the cause of problems that are usually blamed on others and how to identify policies that must be followed to improve this situation. In the context of project management, System Dynamics approaches a holistic view of the project management process and reveals how most project management decision-making policies are the cause of problems [10].

System Dynamics are depictions of system behavior that have interdependent relationships and change with time. System Dynamics have the advantage of connecting and modeling from various aspects of the analysis so that all aspects have full relevance. Besides, the system dynamics approach can also describe the dynamics of the behavior of time to know the past, present, and future conditions. System Dynamics was chosen as simulation techniques because of their strong ability to analyze the reciprocal relationships and feedback that exist in complex systems [11]. System Dynamics simulation methods have been used in various applications including social science and also in various fields of engineering. There are several stages in system dynamics modeling to help create a model and simulation [12]. Figure 1 shows the steps of the research using system dynamics.

Step 1: The Drafting Concept to formulate the background of the problem and make a pattern of activities to produce a mental model stated in a causal loop diagram.

Step 2: Model Making to make stock-flow diagrams based on previously generated causal-loop diagrams.

Step 3: Data Input which enters primary and secondary data into the stock-flow diagram for modeling.

Step 4: Model Simulation to run the model that is set to produce results in a period.

Step 5: Model Validation to verify the suitability of the model.

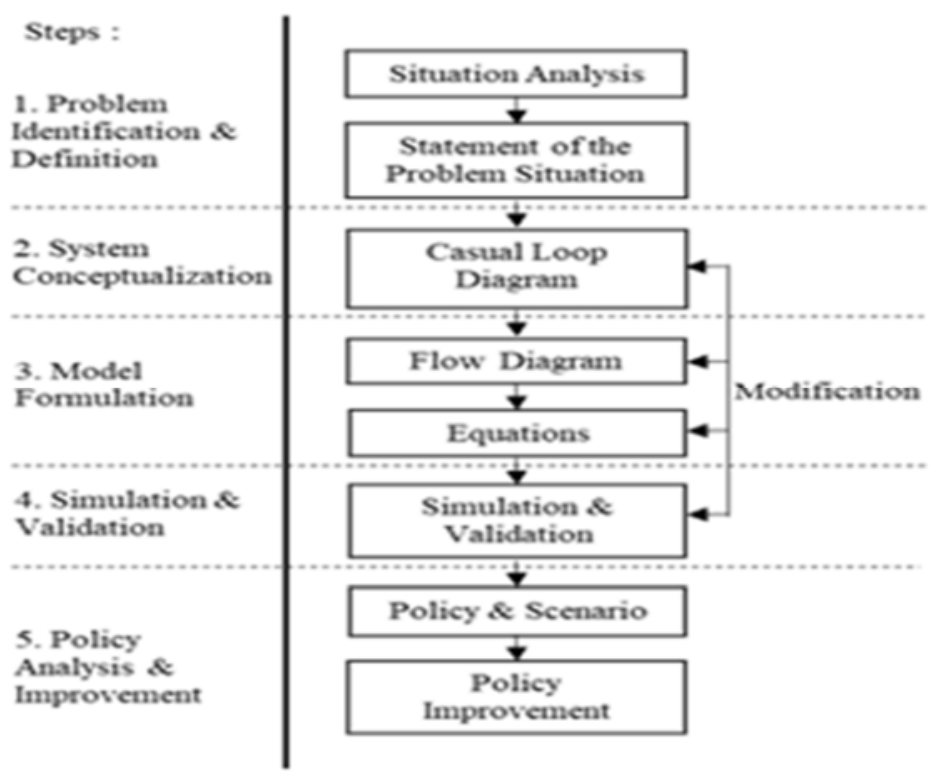

Fig 1. Research Method 
System Dynamics simulations are based on the feedback theory used to study complex systems and effective policymaking [13]. Construction projects are included in the complex category, consisting of several interdependent components and involving various feedback processes and involving quantitative and qualitative data. To manage this complexity correctly, the System Dynamics method is used because of its ability to represent systems with dynamic characteristics that can be simulated to predict the future from year to year according to certain parameters.

Several studies in the field of construction project management using system dynamics methods such as developed the system dynamics model to estimate the performance of construction projects in eight performance measures [14]. Developed system dynamics model to analyze the effect of critical success factors in the publicprivate partnership infrastructure project [15]. Using system dynamics to see the risk of delays in infrastructure projects [13], Using system dynamics to see factors that could increase construction productivity [16], and using system dynamics to optimize the recycling and collection of waste materials in closed-loop supply chains [17].

\section{RESULT AND DISCUSSION}

\section{A. Situation Analysis}

The port has a very important role in economic activities, especially for maritime countries like Indonesia. Around $90 \%$ of trading activities, both domestic and international (export-import) are carried out through ports, therefore, activities at ports determine the smoothness of inter-island and inter-country trade. As the main means of sea transportation, the port becomes one of the links in the national logistics supply chain that plays a significant role in increasing the efficiency and effectiveness of the national logistics supply chain. Delay in the provision or development of infrastructure can result in bottle-neck transportation and various development obstacles that disrupt economic growth [18]. Therefore, good and effective transportation infrastructure at ports is needed to support the improvement of a country's economic performance.

Tanjung Perak Port is one of the largest ports in Indonesia, with a total area of 5400 ha and 6 terminals are serving domestic and international activities. In addition to being one of the largest ports in Indonesia, container flow activity at Tanjung Perak port is also very dense and continues to grow every year. Based on data from Indonesia Supply Chain, The number of export and import activities in Tanjung Perak Port in 2018 reached 28,811 tons (in thousand) with an increase of 2.18\% growth per year from 2014 to 2018. One problem related to sea transportation is the problem of logistics costs in Indonesia which are still high caused by many interrelated things. One obstacle that triggers high logistics costs is the inadequate infrastructure needs and the loading and unloading activities at the port that have not been maximized, causing goods congestion. That is, a lot of goods are piled up somewhere, causing congestion of goods flow. This condition will cause the mobilization of the flow of goods to stop or commonly called stagnation.

These conditions can disrupt the flow of container activity at the port of Tanjung Perak, where every year the flow of containers tends to increase. To overcome the problem of piling up of goods due to congestion, the manager of the Port of Tanjung Perak has gradually increased the installed capacity of the port. However, this step can only overcome the problem of congestion of goods in a few years or short term. If we look at the rate of containers that tends to increase every year with installed capacity at the port, it is necessary to develop infrastructure in the form of alternative transportation modes to transport containers. By providing alternative transportation infrastructure, companies with good and cost-effective access can provide a better performance, reduce delivery time, increase production, consumption, and trade to increase economic growth.

Besides, with the alternative transportation infrastructure, it is expected to also be able to overcome the problem of congestion that is triggered by port operations in mobilizing goods to the hinterland area still using the truck mode to transport containers. The approach to using a system dynamics is expected to help provide solutions and choices. Besides, by including government scenarios and policies in a system dynamics model. It can help to find the best decision between infrastructure development by adding installed port capacity or by developing alternative transportation infrastructure.

\section{B. Causal Loop Diagram (CLD)}

Causal Loop Diagrams are part of system thinking and are diagrams that help visualize how interconnected variables affect each other. Tools are needed to create a system concept that focuses on the structure and behavior of the system from time to time using some causal causation and [8]. Causal Loop Diagrams are important tools that help in visualizing how the different variables in a system are interrelated and represent the feedback structure of a system [14]. Methods based on defining important components of a system, establishing causal relationships between these components with causal causes, and running scenarios or various conditions in the future to see how the system can react under various possible changes or uncertainty [19].

Causal Loop Diagrams consist of causal causes and effects which are shown graphically by arrows connecting variables [8]. The diagram shows how one variable affects the other because each relationship between variables has a polarity, that is, positive (+) or negative (-) arrows that indicate whether there is an increase or decrease in the relationship between two variables [13]. The interrelation and feedback process in the system can record a 
model that represents in causal Loop diagram. The main purpose of a Causal Loop Diagram is to describe a causal hypothesis, thus making the presentation of the structure in the aggregate form [20].

The level of detail needed to further illustrate each parameter depends on the needs of the desired results. In this study, parameters are decomposed at one to two levels at most to illustrate how complexity can be systematically decomposed. Figure 2 can be seen as a causal relationship between causal, wherewith the need for goods causes an increase in the need for imports and exports, consequently, the number of exports and imports will increase. in addition to the demand for goods, the number of exports and imports is influenced by the growth of import exports which results from the economic growth in the region. The number of exports and imports continues to increase causing the need for containers to also increase, with the increasing need for containers causing growth in the availability of new containers also increases so that the number of containers is also obtained. The number of containers causes an adjustment to port capacity and the need for port expansion. From the expansion of the area, it can be obtained the growth of port capacity expansion as an accumulation of total port capacity. The results of the number of containers with total port capacity can be obtained from the ratio of port absorption to containers that operate. In this study, the limitation of making causal loop diagrams between parameters is only the capacity of the port and the number of containers in operation. The causal loop diagram in this study is based on the existing supply and demand needs at the port and results in new transportation infrastructure needs to maximize activities at the port

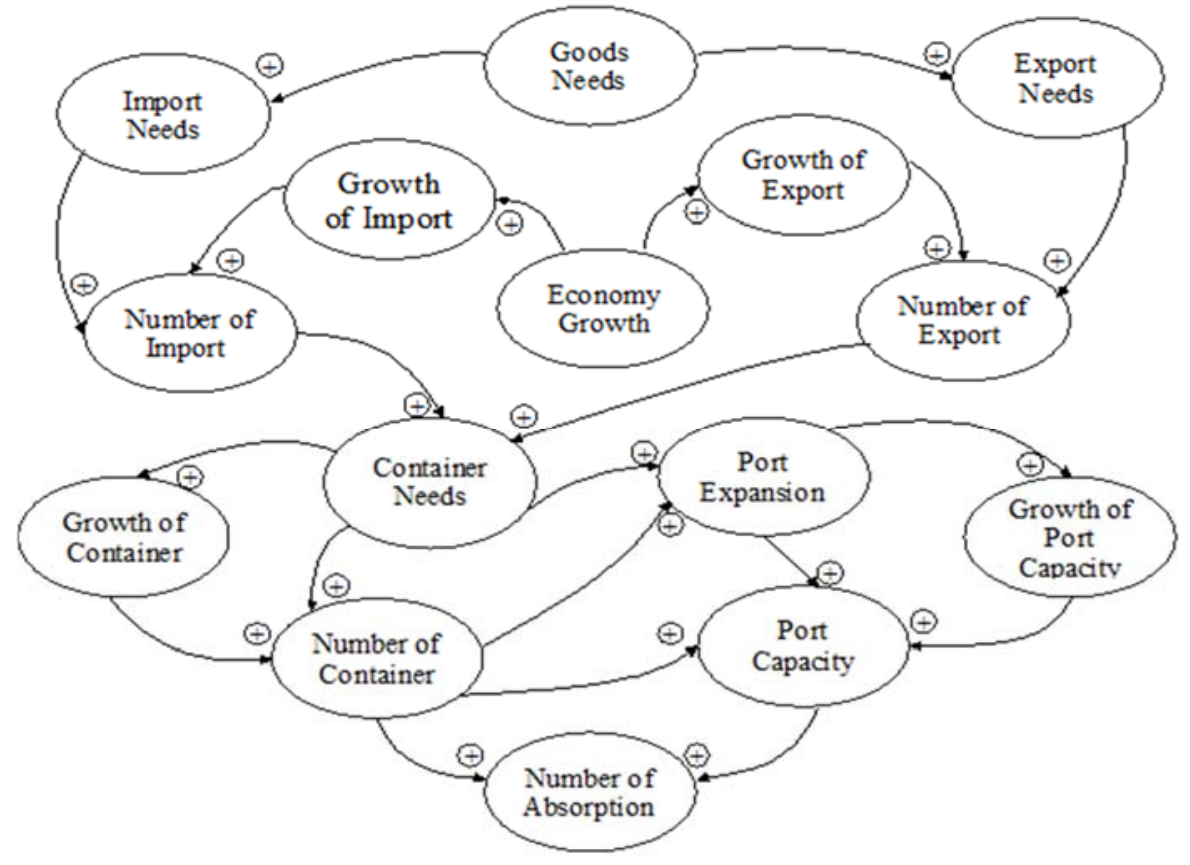

Fig 2. Causal Loop Diagram

\section{Model Formulation}

System Dynamics method is carried out by constructing a model of an observational system or Stock-Flow Diagram. The model is a depiction of the actual situation by showing the main parts that want to be highlighted. In making this simulation model, the most important thing is to define the problem to be studied, determine the problem boundaries and the time horizon of observation and get the variables that influence the observational system to make a hypothesis about the behavior of the system being modeled. Then the variables are connected by arrows to show the causal relationship. From the causal relationship that has been made, a flow chart will be made to run the model that has been made. In this flow diagram parameters or values will be entered according to the real situation [21].

The main components in the Causal Loop Diagram are then incorporated into the Stock-Flow Diagram model. The components in Stock-Flow Diagram consist of four main components namely stock, flow, valve, and starting [20]. Stock (rectangle) is the accumulation of the main system variables during simulation time. Flows, on the other hand, produce an amount that enters a certain stock as "inflow", or out of stock as "outflow" from time to time. The valve is a flow generator (based on relationships in the model) and controls the amount of inflow and outflow during simulation time. Clouds are also entry points or boundaries in the model. 
In stock-flow diagrams, some equations represent the basic mathematics behind stock and flow calculations. Using equation 1, the rate of change in the stock variable is determined based on the difference between the entry and exit parameters. Meanwhile, the value of the annual inventory variable $(\mathrm{t})$ during simulation time can also be determined using equation 2.

$$
\begin{gathered}
\frac{d(\text { Stock })}{d t}=\operatorname{Inflow}(t)-\text { Outflow }(t) \\
\operatorname{Stock}(t)=\int_{t o}^{t}[\operatorname{Inflow}(s)-\operatorname{Outflow}(s)] d s+\operatorname{Stock}(\text { to })
\end{gathered}
$$

In this study, the formulation model is performed on each parameter that determines the number of containers and port capacity. By using the Powersim Studio 10 software the formulation model is carried out to get maximum results and following the real conditions that have occurred for several years. The number of exports/imports is obtained from the sum of export/import growth each year with the number of containers in the previous year. The value of export/import growth is obtained by multiplying the rate of import/export needs with the number of exports/imports of the previous year. The form of the formulation to get the amount of export/import growth and total export/import needs can be seen in the equation below.

$$
\begin{gathered}
\frac{d}{d t}(G o I)=I N \text { Rate }(t) x \operatorname{NoI}(t) \\
\operatorname{NoI}(t)=\int_{t o}^{t}[I N \text { Rate }(s) x \operatorname{NoI}(s)] d s+N o I(t o) \\
\frac{d}{d t}(G o E)=E N \text { Rate }(t) x N o E(t) \\
N o E(t)=\int_{t o}^{t}[E N \text { Rate }(s) x N o E(s)] d s+N o E(t o)
\end{gathered}
$$

Where,

GoI : Growth of Import

IN Rate : Import Needs Rate

NoI : Number of Import

GoE : Growth of Export

EN Rate: Export Needs Rate

NoE : Number of Export

Meanwhile, for the growth of container availability, it is obtained from the multiplication of the number of containers in the previous year at the rate of container demand. For the number of containers obtained from the sum of export/import values at the port, while for the growth of container availability is obtained by multiplying the number of containers at the rate of container needs. Form of formulation to get the amount of port capacity and the number of containers can be seen in the equation below.

$$
\begin{gathered}
\frac{d}{d t}(G o C)=N o C(t) x C N \text { Rate }(t) \\
N o C=N o I(t)+N o E(t) \\
N o C(t)=\int_{t o}^{t}[C N \text { Rate }(s) x N o C(s)] d s+N o C(\text { to }) \\
\frac{d}{d t}(G o P C)=P C(t) x P E \operatorname{Rate}(t) \\
P C(t)=\int_{t o}^{t}[P C(t) x P E \operatorname{Rate}(t)] d s+P C(t o)
\end{gathered}
$$

Where,

$$
\begin{aligned}
& \text { GoC : Growth of Container } \\
& \text { NoC : Number of Container } \\
& \text { CN Rate : Container Needs Rate } \\
& \text { GoPC : Growth of Port Capacity } \\
& \text { PC : Port Capacity } \\
& \text { PE Rate : Port Expansion Rate }
\end{aligned}
$$

From the results of the port capacity with the number of containers in operation, it can be obtained the value of the absorption capacity of the port to the number of containers operating each year. In this model, each parameter is added at a different rate, its function is to help the simulation results and scenarios. This is because each parameter is influenced by many aspects, certain policies, and conditions outside the initial target port plan. Figure 3 can be seen as the results of the stock-flow diagram modeling that has been imported by the model formulation. 


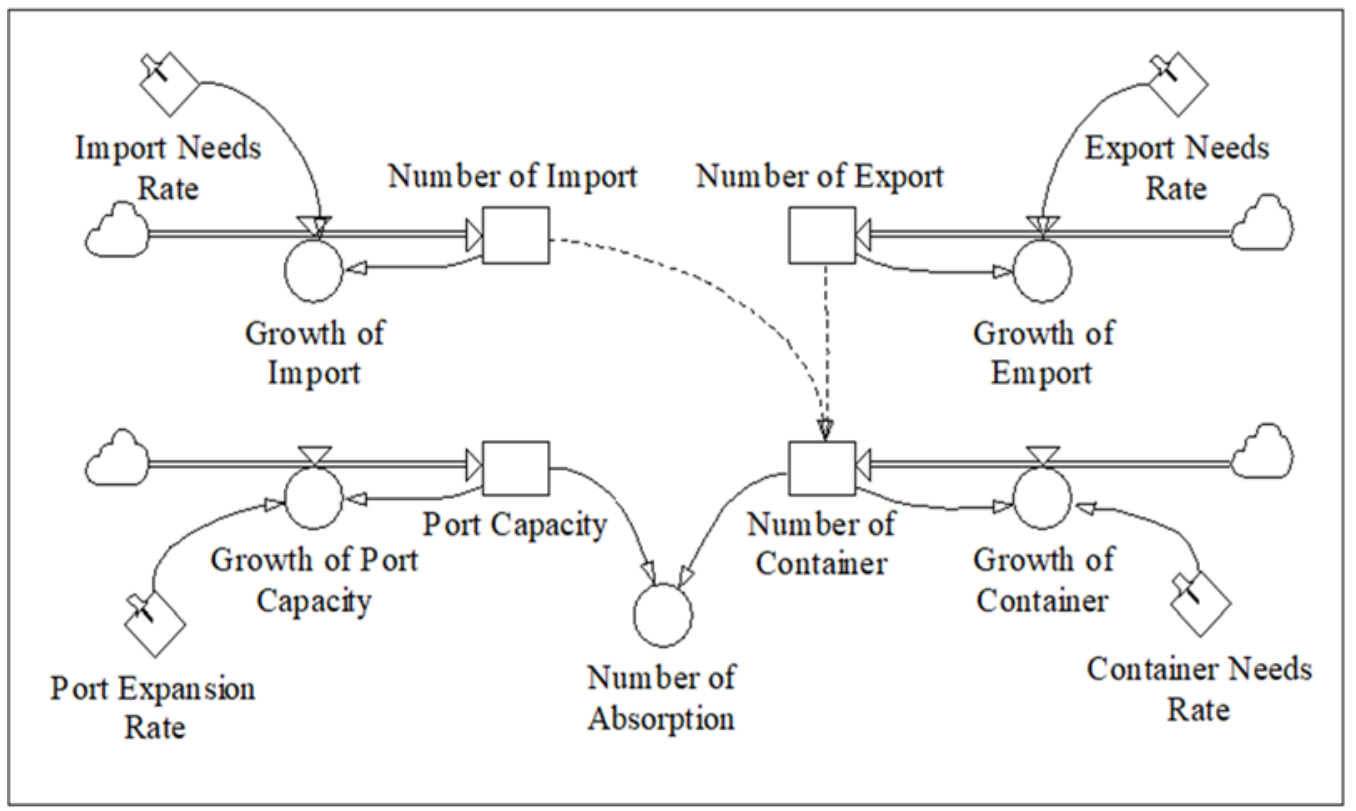

Fig 3. Stock Flow Diagram

\section{Model Validation}

Model validation can be done by comparing data collected from real-world systems with data generated from simulation models. The model validity test is to test the value of the number of containers between the simulation value and the actual value [22]. The output of the model is very dependent on data input, data collection and validation must be done correctly. Verification through the experts involved and through relevant literature reviews shows how realistic the conceptual model is in representing variables and relationships in the system [23]. The replication number is calculated using the formula presented below.

$$
N_{m}=\left(\frac{S(m) x t_{m-1,1-\frac{\varphi}{2}}}{\chi_{(m)} \varepsilon}\right)
$$

Where $\mathrm{Nm}$ is the number of replications, $\mathrm{Sm}$ is the standard deviation of the data, $\mathrm{t}$ is the test statistic obtained from the t-table, $\mathrm{m}$ is the initial number of replications assumed, is the $90 \%$ confidence interval, $\mathrm{X}(\mathrm{m})$ is the average data and is the percentage of errors allowable. Validation in this study uses real data and simulation results on a total container with, for the number of replications is 5, from 2014 to 2019. In table 1, can be seen as the results of the model validation test based on the simulation results of the model with real data. So a relative error number can be obtained for each replication.

Table 1: Model Validation Test

\begin{tabular}{cccc}
\hline Year & The Real Value & The Simulation Value & Relative Error \\
\hline 2014 & 4,404 & 4,404 & 0,0000 \\
2015 & 4,731 & 4,664 & 0.0142 \\
2016 & 5,083 & 4,939 & 0.0283 \\
2017 & 5,461 & 5,230 & 0.0423 \\
2018 & 5,866 & 5,539 & 0.0557 \\
2019 & 6,303 & 5,866 & 0.0693 \\
\hline
\end{tabular}

From the results of the model validation test, the error value obtained in this model is $3 \%$. Based on the $90 \%$ level of confidence or simulation models are considered valid if the average comparison of real data and simulation $\leq 5 \%$, then the simulation results of the model in this study are valid.

$$
\begin{aligned}
\text { Mean Error } & =a b s \frac{\bar{x} T C_{(\text {real })}-\bar{x} T C_{(\text {model })}}{\bar{x} T C_{(\text {real })}} \\
& =\frac{(5308-5107)}{5308} \times 100 \% \\
& =3,79 \% \text { (Valid) }
\end{aligned}
$$




\section{E. Simulation}

By using system dynamics methods we can simulate several scenarios or parameters that have high sensitivity. After the model formulation is entered into the Stock-Flow Diagram, results in normal conditions can be obtained. After that, we can do several scenarios by changing the auxiliary or rate for each parameter. The simulation can be carried out with a basic scenario consisting of certain assumptions, and not the right parameters such as population growth, regional development policies, and feedback [24].

In this study, simulations were carried out over the next 20 years from 2014 to 2034 to see the condition of the effects of related parameters, especially the effects of increasing port installed capacity. Forecasting demand in the market cannot be done using past trends, where a country's economic situation tends to fluctuate and government policies will produce adjustments [12]. The simulation starts in 2014 because in 2016 there was an increase in the installed capacity of the port, assuming construction activities lasted for 2 years or started in 2014.

The simulation focuses on the port capacity parameter because this parameter determines when to increase port capacity or develop alternative transportation modes. There are two simulated scenarios, namely the condition where the port capacity addition is carried out in a minor manner, assuming the absorption of container flows can run smoothly, then the second condition where port capacity development is carried out on a major basis and following planned targets.

In Scenario 1, the simulation is done by entering the port's installed capacity following the existing data and assuming there is no major port capacity increase. The value of container export and import growth needs uses the rate of exports and imports in the last 10 years, where the average rate of container export growth is 3.14\% and for the average import growth rate of $1.77 \%$. For the rate of container flow growth, the average container flow growth at the port of Tanjung Perak is $7.43 \%$ per year in line with the increase in economic growth. Meanwhile, the average port capacity growth rate is $4.66 \%$.

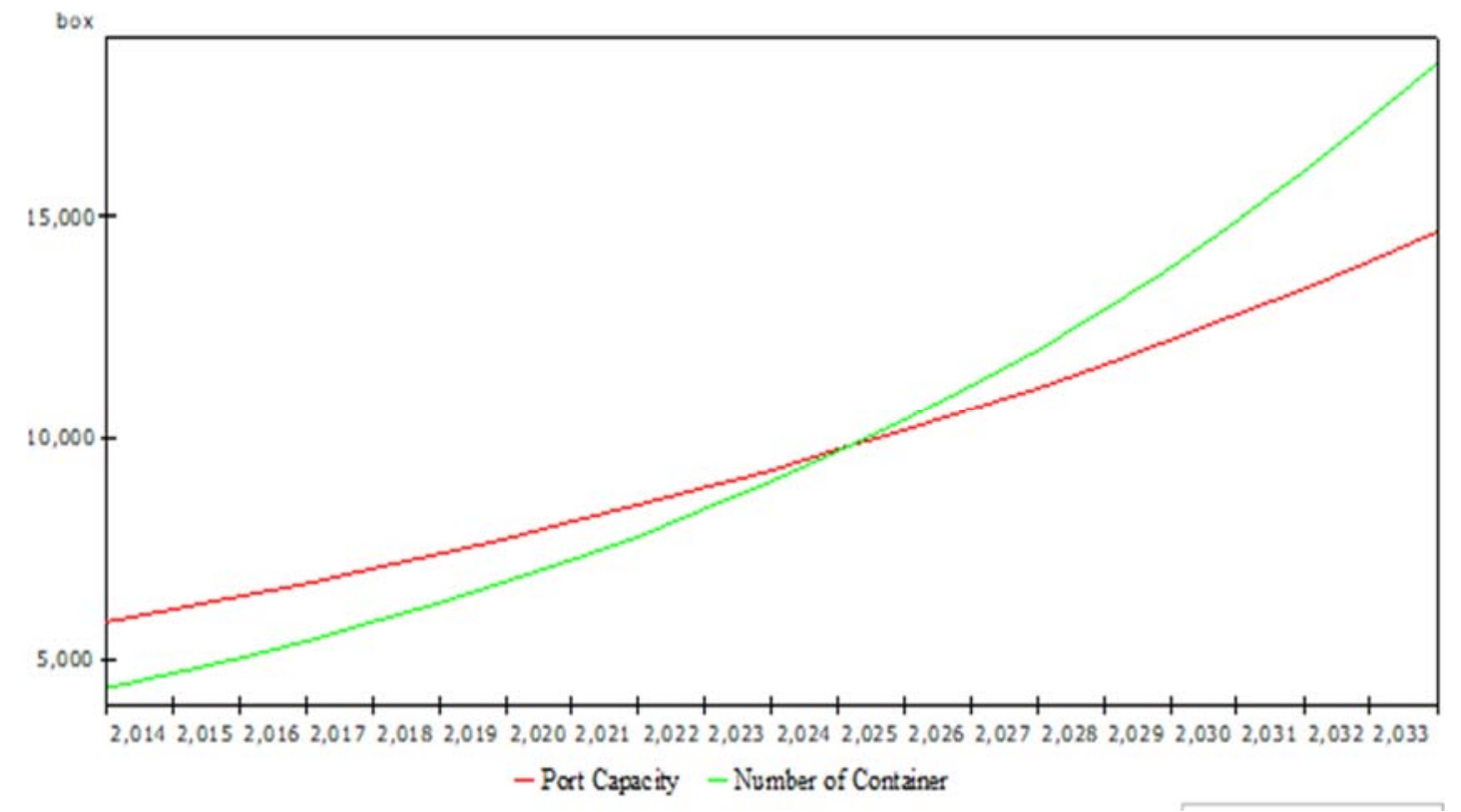

Fig 4. Scenario 1

The port's installed capacity is based on the BOR (Berth Occupancy Ratio) or dock use level of $80 \%$. So that the installed capacity in Tanjung Perak port in 2014 amounted to 5 million boxes and so far there has been an increase in installed capacity to 7 million boxes in 2016. In figure 4 we can see the results of scenario 1 simulation, from the results of this simulation it can be seen that by entering the parameters the growth of container flows in the simulation model, port capacity will experience difficulties in serving container flow activities at the port to the maximum in 2026. This is due to container flow growth which tends to increase each year and is not proportional to port capacity. From the results of simulation 1, it can be concluded that it is necessary to have a policy from the port manager in serving container activities at the port. One of the policies that can be done is by having an alternative mode of transportation to help smooth the flow of containers at the port. Through this simulation it can also be seen, the market or target of containers that must be absorbed if alternative transportation modes are developed. From the simulation results it can be seen that with the existence of alternative transportation infrastructure, the minimum target that must be absorbed by this mode of transportation is an average of $11.11 \%$ until 2034 from the total container flow at the port. 
In Scenario 2, the simulation is carried out by entering the port's installed capacity following the existing data and following the planned port/target capacity. The value of container export and import growth needs uses the rate of exports and imports in the last 10 years, where the average rate of container export growth is $3.14 \%$ and for the average import growth rate of $1.77 \%$. For the rate of container flow growth, the average container flow growth at the port of Tanjung Perak is $7.43 \%$ per year in line with the increase in economic growth. Meanwhile, the average port capacity growth rate follows the planned port capacity planned until 2030 . For the target installed capacity at the port in 2016, there will be an increase in installed capacity to 7 million boxes or an increase of $25.6 \%$ from the initial port capacity, then the target in 2023 installed capacity reached 9 million boxes or an increase of $23.8 \%$ from the capacity of the initial port, and in 2030 it reached around 11 million boxes or an increase of $17.5 \%$ from the capacity of the initial port.

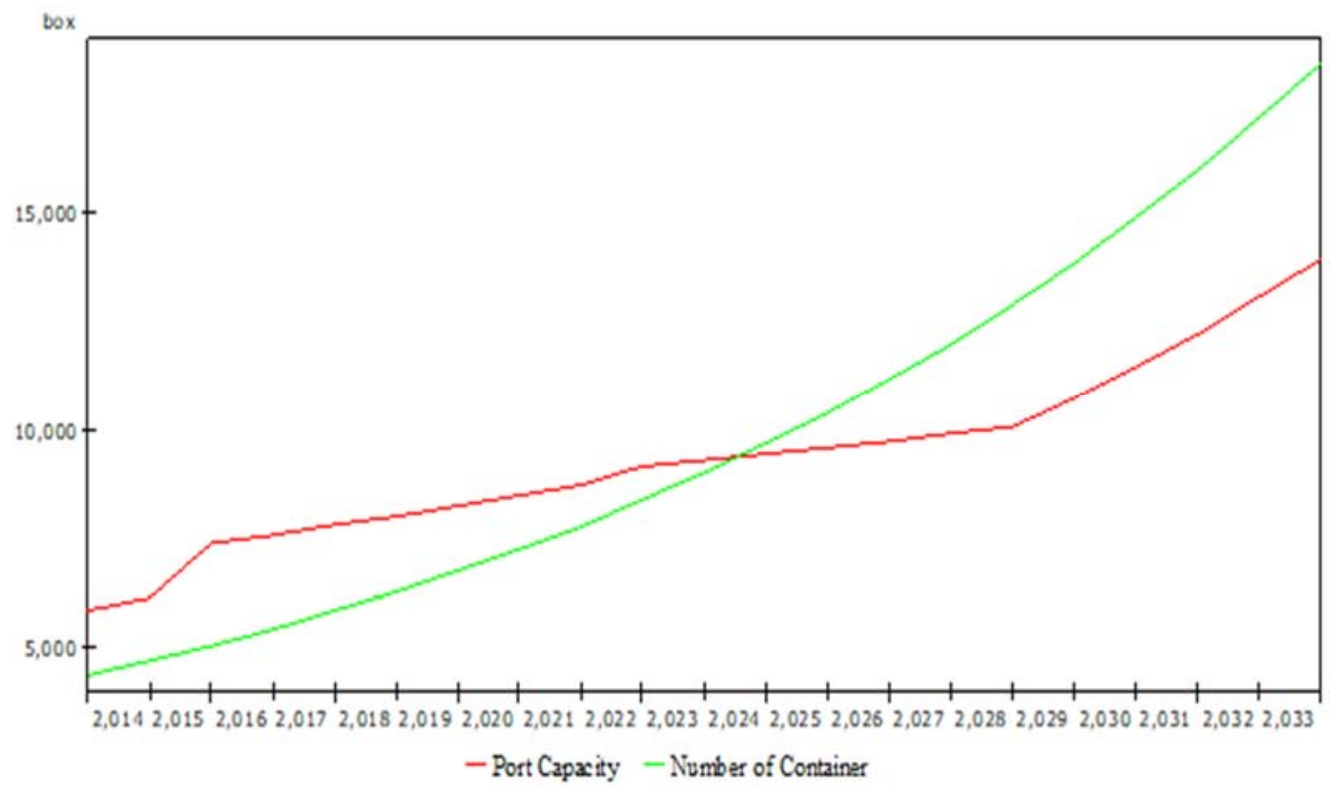

Fig 5. Scenario 2

In Figure 5 we can see the results of scenario 2, although the pattern of increasing port capacity follows the plan to increase port capacity until 2030, the capacity of the port is still unable to absorb containers optimally. This is because the growth of container flows tends to increase every year and is not proportional to the port capacity. It can be seen that in 2025 there will be conditions where the installed capacity of the port will be difficult to serve containers which tend to increase every year. From the results of this scenario 2 simulations, it can be concluded that it needs policies from the port manager in serving container activities at the port. One of the policies that can be done is by having an alternative mode of transportation to help smooth the flow of containers at the port. Through this simulation it can also be seen, the market or target of containers that must be absorbed if alternative transportation modes are developed. From the simulation results it can be seen that with the existence of alternative transportation infrastructure, the minimum target that must be absorbed by this mode of transportation is an average of $10 \%$ up to 2034 from the total container flow at the port.

\section{CONCLUSION}

System dynamics can be used in industrial systems as business process reengineering, financial analysis, resource planning, and strategic planning. In this research system dynamics are used to determine the best strategy in planning alternative modes of transportation development, and if further developed, we can conduct analyzes and simulations for other parameters that have a causal relationship of cause and effect of the development of the transportation mode. In conducting analysis using system dynamics, making casual loop diagrams and formulation models become the determining factors in the analysis. Also in making casual loop diagrams, it is necessary to have a limit or level of parameters to be analyzed.

The simulations are carried out over the next 20 years to see the condition of the related parameter effects, especially the effects of increasing port installed capacity. The simulation starts in 2014 because in 2016 there was an additional installed capacity of the port, assuming construction activities lasted for 2 years or started in 2014. The simulation conducted in this study uses two scenarios. In scenario 1, it will be obtained in 2022 that conditions will occur where the installed capacity of the port cannot carry the maximum amount of container flow or on average around $7.69 \%$ of the container will not be optimally absorbed. The results of scenario 2 are obtained, in 2025 there will be conditions where the installed capacity of the port cannot carry the maximum amount of container flow or on average around $10 \%$ of containers will not be absorbed optimally. 
From the results of the simulations of the two scenarios, it can be found that even with the addition of port capacity with short-term, medium-term and long-term plans it is still unable to absorb the container flow optimally because container flow rates tend to increase each year. From the simulation results of the two scenarios, it can also be seen that although there is an increase in port capacity, other efforts are still needed to smooth the container flow at the port, one of them is by developing infrastructure in the form of alternative transportation to absorb containers that are not transported optimally.

\section{ACKNOWLEDGMENT}

The author wants to express thanks for the support given by the PT Pelindo III and Mercu Buana University who provided insight and expertise that greatly assisted the research, especially because they have provided input, opinions, and information for this research.

\section{REFERENCES}

[1] Moschouli, E., Murwantara, R., \& Vanelslander, T. (2019). Research in Transportation Economics Cost performance of transport infrastructure projects before and after the global financial crisis (GFC): Are differences observed in the conditions of project performance? Research in Transportation Economics, 75(December), 21-35.

[2] Heyoushi \& Ming, L. (2007). System Dynamics Analysis on the Regional Transport Infrastructure and Social Economic Development. International Conference on Transportation Engineering, 642-648.

[3] Kim, E., Hewings, G. J. D., \& Amir, H. (2016). Research in Transportation Economics Economic evaluation of transportation projects : An application of Financial Computable General Equilibrium model. Research in Transportation Economics, 61(3), 44-55.

[4] Wang, L., \& Zhang, X. (2017). System Dynamic Model for Simulating Demand-Supply Interaction of Railway Express Freight System. Mathematical Problems in Engineering, 1-10.

[5] Husin, A. E., Berawi, M. A., Dikun, S., Ilyas, T., \& Berawi, A. R. B. (2015). Forecasting demand on mega infrastructure projects: Increasing financial feasibility. International Journal of Technology, 6(1), 73-83.

[6] Mohammed, S. R., Naji, H. I., \& Ali, R. H. (2019). Impact of the Feasibility Study on the Construction Projects. IOP Conference Series: Materials Science and Engineering, 518(2).

[7] Cagatay, M., \& Camgoz, H. (2019). The Asian Journal of Shipping and Logistics The System Dynamics Modelling for Container Capacity \& Transportation Planning Policies. The Asian Journal of Shipping and Logistics, 35(4), 200-212.

[8] Sterman, J. D. (2001). System Dynamics Modeling: Tools for Learning in Complex World. California Management Review Reprint Series. 43(4).

[9] Banerjee, D., Jagadeesh, P., \& Rao, R. P. (2018). A system dynamic approach of technical risk modeling in transportation megaprojects. International Journal of Civil Engineering and Technology, 9(8), 627-635.

[10] Al-kofahi, Z. G., Mahdavian, A., \& Oloufa, A. (2020). System dynamics modeling approach to quantify change orders impact on labor productivity $1:$ principles and model development comparative study. International Journal of Construction Management, 1-12.

[11] Anh, M., Lê, T., \& Law, K. H. (2009). System Dynamic Approach for Simulation of Experience Transfer in the AEC Industry. (October), 195-203.

[12] Susetyo, B., \& Raharjo, H. M. (2019). Modelling in residential property market to forecast demand using system dynamics. International Conference on Engineering, Technology, and Industrial Application, 1-7.

[13] Pagoni, E. G., \& Patroklos, G. (2019). Simulation Modelling Practice and Theory A system dynamics model for the assessment of national public - private partnership programmes ' sustainable performance. Simulation Modelling Practice and Theory, 97(December), 101949.

[14] Leon, H., Osman, H., Georgy, M., \& Elsaid, M. (2018). System Dynamics Approach for Forecasting Performance of Construction Projects. Journal of Management in Engineering, 34(1).

[15] Ullah, W., Takaaki, N., Mohammad, N., \& Zaman, R. (2017). Understanding climate change vulnerability , adaptation and risk perceptions at household level in Khyber Pakhtunkhwa , Pakistan International Journal of Climate Change Strategies and Management, 10(3), $359-378$.

[16] Seresht, N. G., \& Fayek, A. R. (2018). Dynamic Modeling of Multifactor Construction Productivity for Equipment-Intensive Activities. American Society of Civil Engineers, 144(9), 1-15.

[17] Golroudbary, S. R., \& Zahraee, S. M. (2015). Simulation Modelling Practice and Theory System dynamics model for optimizing the recycling and collection of waste material in a closed-loop supply chain. Stimulation Modelling Practice and Theory, 53(4), 88-102.

[18] Kim, J. (2019). Estimating the social cost of congestion using the bottleneck model. Economics of Transportation, 19(September), 100119.

[19] Yildiz, A. E., Ph, D., Dikmen, I., \& Birgonul, M. T. (2020). Using System Dynamics for Strategic Performance Management in Construction. American Society of Civil Engineers 36(2).

[20] Dangerfield, B. (2016). System Dynamics Theory and Applications. Springer.

[21] P Mupfumira, P., \& Wirjodirdjo, B. (2015). An Economically Sustainable Urban Public Transport Framework: System Dynamics Modelling Approach to Reduce Public Transport Liberalisation Impact in Harare City. International Journal of Science Technology and Society International Journal of Science Technology and Society. Special Issue: Design Innovations for Sustainable Development, 3(2), $11-21$.

[22] Zhang, M., Chen, H., Zhang, C., \& Wu, Z. Study on the Transportation Development Strategy in Economic Zone Based on System Dynamics. American Society of Civil Engineers, 2433-2442.

[23] Siraj, N,B. \& Fayek, A,R. Fuzzy System Dynamics for Modeling Construction Risk Management. American Society of Civil Engineers, $1990,2411-2421$

[24] Jo, H., Lee, H., Suh, Y., Kim, J., \& Park, Y. (2015). A dynamic feasibility analysis of public investment projects: An integrated approach using system dynamics and agent-based modeling. International Journal of Project Management, 33(8), 1863-1876. 